\title{
SINGULARITAS SEMU PADA RUANG-WAKTU REISSNER-NORDSTRÖM
}

\author{
I Gusti Ngurah Yudi Handayana'1), Lily Maysari Angraini ${ }^{1)}$ \\ ${ }^{1)}$ Program Studi Fisika, FMIPA, Universitas Mataram, Mataram, NTB, Indonesia \\ Corresponding author : I Gusti Ngurah Yudi Handayana \\ E-mail : ngurahyudi@unram.ac.id
}

Diterima 01 November 2019, Disetujui 19 November 2019

\begin{abstract}
ABSTRAK
Penelitian ini mengkaji singularitas semu pada metrik Reissner-Nordström, yang merupakan solusi persamaan medan Einstein untuk model partikel bermuatan. Kajian dilakukan dengan menganalisis titik-titik singular pada metrik, menghitung tensor kelengkungan Riemann, serta menghitung scalar Kretschmann pada titik-titik tersebut. Perhitungan dilakukan dengan bantuan program Maxima. Hasilnya, singularitas nyata hanya terjadi pada $r=0$, sedangkan singularitas semu terjadi pada $r_{ \pm}=M \pm \sqrt{M^{2}-Q^{2}}$. Singularitas semu tersebut merupakan representasi dari horizon peristiwa. Terdapat tiga kemungkinan situasi pada horizon peristiwa. Hal menarik terdapat pada situasi $r=M$, dimana terjadi keseimbangan antara massa dan muatan yang memungkinkan tarikan gravitasi dan tolakan elektromagnetik saling meniadakan. Penelitian ini juga menghasilkan persamaan geodesik pada titiktitik yang tidak menghasilkan nilai infinite pada skalar Kretschmaan.
\end{abstract}

Kata Kunci : Kelengkungan Riemann; Metrik Reisner-Nordström; Singularitas; Persamaan Geodesik

\begin{abstract}
This study examines pseudo singularities on the Reissner-Nordström metric which is a solution to Einstein's field equations for charged particle models. The study was carried out by analyzing the singular points on the metric calculating the Riemann curvature tensor, and calculating Kretschmann's scalar at these points. The results show that real singularities only occur at $r=0$, whereas pseudo singularity occurs at $r_{ \pm}=M \pm \sqrt{M^{2}-Q^{2}}$. There is a point of pseudo singularity that representing the event horizon. There are two possible situations on the event horizon. Interesting things are in the case $r=M$, where here is a balance between mass and charge which allows gravitational pull and electromagnetic repulsion to cancel each other. This study also yields the geodesic equation point that not yields infinite value of Kretschmaan scalar.
\end{abstract}

Keywords: Riemann tensor; Reissner-Nordström Metrik; Singularities; Geodesik equation

\section{PENDAHULUAN}

Teori Einstein muncul karena ketidakpuasan pada konsep Newtonian, khususnya pada sistem inersial. Sistem inersial merupakan kondisi yang sulit untuk dilakukan demonstrasi terkait dinamika gerak benda. Pandangan Einstein berdasar pada anggapan adanya saling keterkaitan antara ruang-waktu dan materi-energi. Berbeda dengan konsep Newton, ruang-waktu tidak memiliki eksistensi sendiri, melainkan diciptakan oleh kehadiran materi-energi. Gravitasi dalam relativitas umum tidak lagi merupakan gaya, seperti halnya Newtonian, tetapi merupakan suatu manifestasi kelengkungan ruang-waktu (O'neill, 1983; Grön, 2011; Carroll, 2004; Joshi, 2007).

Ruang-Waktu Reissner-Nordström merupakan ruang-waktu 4 dimensi yang mengandung metrik Reissner- Nordström.
Metrik Reissner-Nordström merupakan solusi bagi persamaan medan Einstein untuk lubang hitam bermuatan dan termasuk dalam model partikel berotasi (O'neill,1983; Bernard, 2017). Persamaan medan Einstein adalah persamaan kelengkungan ruang-waktu berupa“persamaan medan". Persamaan medan ini berlaku umum untuk segala sistem dinamika partikel. Persamaan ini tidak mudah untuk dicari solusi eksaknya, karena merupakan persamaan kelengkungan ruang-waktu. Persamaan medan ini dikarakterisasi oleh tensor energimomentum dengan matematika yang tidak sederhana (Grön, 2011).

Kajian metrik Reissner-Nordström telah dilakukan oleh Graves dan Brill (1960). Kajian yang dilakukan meliputi transformasi metrik untuk menghindari singularitas semu menggunakan transformasi Kruskal, sebagai pengembangan dari metrik Schwarzschild. 
Hasilnya, perilaku partikel yang didapat mirip dengan Schwarzschild. Wald (1979) mencoba membangkitkan solusi persamaan EinsteinMaxwell linear yang mendeskripsikan peturbasi lubang hitam Reissner-Nordström. Namun, belum ada yang menunjukkan bukti terkait singularitas pada solusi ReissnerNordström.

Solusi-solusi yang ditawarkan untuk persamaan medan Einstein terkadang mengandung nilai tak hingga pada titik tertentu. Ketakhinggaan nilai metrik ini disebut singularitas. Singularitas ini terkadang adalah singularitas tak nyata yang diakibatkan oleh kesalahan pemilihan koordinat (metrik) maupun oleh hal lainnya (Penrose, 1965; Joshi, 2007). Penelitian ini mengkaji singularitas semu pada metrik Reissner-Nordström. Berbagai metode mesti dilakukan untuk menunjukkan singularitas semu pada suatu metrik. Kajian dilakukan dengan menganalisis titik-titik singular pada metrik, menghitung tensor kelengkungan Riemann, serta menghitung skalar Kretschmann pada titik-titik tersebut. Kemudian, persamaan geodesik dituliskan di sekitar titik singularitas.

\section{TEORI}

Pada suatu model lubang hitam bermuatan dapat dinetralkan dengan cepat melalui interaksi dengan suatu materi pada sekitar lubang. Pada situasi ini, simetri bola tetap menjadi pilihan dalam menentukan metrik Reissner-Nordström yang diberikan sebagai berikut (Carroll, 2004)

$$
\begin{aligned}
d s^{2}= & -\left(1-\frac{2 M}{r}+\frac{Q^{2}}{r^{2}}\right) d t^{2}+\left(1-\frac{2 M}{r}+\frac{Q^{2}}{r^{2}}\right)^{-1} d r^{2} \\
& +r^{2} d \theta^{2}+r^{2} \sin ^{2} \theta d \phi^{2}
\end{aligned}
$$

dengan $M$ merupakan massa lubang sedangkan $Q$ merupakan muatan listrik total dari lubang. Berdasarkan persamaan Medan Einstein (Carroll, 2004)

$$
G_{\mu \nu}=R_{\mu \nu}-\frac{1}{2} g_{\mu \nu} R
$$

maka membuktikan bahwa metrik ReissnerNordström merupakan solusi persamaan medan harus melalui sejumlah tahapan, seperti menghitung Tensor energi-momentum $\left(G_{\mu \nu}\right)$, tensor Ricci $\left(R_{\mu \nu}\right)$ dan skalar Ricci $(R)$ yang telah dilakukan oleh Berdnard (2017).

\begin{tabular}{ccc}
\multicolumn{2}{c}{ Berdasarkan metrik Reissner- } \\
Nordström (1), dapat dilihat bahwa
\end{tabular} kemungkinan terjadinya singularitas ada pada $r=0$, yang membuat komponen metrik $g_{t t}$ bernilai takhingga. Selain itu jika diambil bagian

$$
\frac{2 M}{r}-\frac{Q^{2}}{r^{2}}=1
$$

maka nilai komponen $g_{r r}$ bernilai tak hingga. Ketakhinggaan inilah yang perlu diselidiki terkait kenyataan singularitas pada metrik Reissner-Nordström.

Singularitas merupakan sebaran massa yang terpusat pada suatu titik yang akhirnya mencapai batas maksimal. Hal ini menyebabkan kelengkungan ruang-waktu pada titik tersebut tidak dapat dipertahankan. Hal ini membuat titik tersebut akhirnya "berlubang" yang sering disebut sebagai lubang hitam.

\section{METODE PENELITIAN}

Singularitas pada ruang-waktu dapat dilihat dari solusi metrik yang diajukan. Jika pada metrik terdapat titik dimana terjadi nilai tak berhingga, maka dapat diduga disana terjadi singularitas. Namun, untuk menentukan apakah singularitas itu nyata atau semu, maka mesti dihitung nilai skalar yang invariant terhadap sistem koordinat, yaktu skalar Kretschmann (Penrose, 1965; Grön, 2011). Adapun skalar Kretschmann diberikan oleh

$$
K=R_{\mu v \alpha \beta} R^{\mu v \alpha \beta}
$$

dengan $\quad R_{\mu v \alpha \beta} \quad$ merupakan tensor kelengkungan Riemann kovarian yang setara dengan

$$
R_{\mu v \alpha \beta}=g_{\mu \mu} R_{\nu \alpha \beta}^{\mu} .
$$

Adapun $g_{\mu \mu}$ merupakan tensor metrik yang diagonal. Tensor kelengkungan Riemann kontravarian diberikan oleh proses menaikkan indeks tensor kelengkungan Riemann (Grön, 2011).

$$
R^{\mu \nu \alpha \beta}=g^{\beta \beta} g^{\alpha \alpha} g^{\nu v} R^{\mu}{ }_{v \beta \beta}
$$

Tensor kelengkungan Riemann sendiri didefinisikan oleh

$$
\begin{aligned}
R^{\mu}{ }_{\nu \alpha \beta} & =\Gamma^{\tau}{ }_{\nu \beta} \Gamma_{\tau \alpha}^{\mu}-\Gamma^{\tau}{ }_{v \alpha} \Gamma^{\mu}{ }_{\tau \beta} \\
& +\Gamma^{\mu}{ }_{\nu \beta, \alpha}-\Gamma^{\mu}{ }_{\nu \beta, \alpha}
\end{aligned}
$$

Dengan $\Gamma_{\nu \beta, \alpha}^{\mu}$ merupakan simbol Christoffel yang diberikan oleh 


$$
\Gamma_{\nu \beta}^{\tau}=\frac{1}{2} g^{\tau \mu}\left(g_{\mu v, \beta}+g_{\mu \beta, v}-g_{\nu \beta, \mu}\right)
$$

Pada ruang-waktu 4 dimensi, maka terdapat 64 komponen untuk simbol Christoffel serta 256 komponen untuk Tensor kelengkungan Riemann. Namun, terdapat simetri yang memberi kemudahan dalam melakukan perhitungan. Simetri tersebut adalah sebagai berikut (Grön, 2011).

$$
\begin{aligned}
& \Gamma_{v \beta}^{\tau}=\Gamma_{\beta v}^{\tau} \\
& R_{v \alpha \beta}^{\mu}=-R^{\mu}{ }_{v \beta \alpha} \\
& R_{\mu v \alpha \beta}=-R_{v \mu \alpha \beta} \\
& R_{\mu v \alpha \beta}=R_{\alpha \beta \mu v}
\end{aligned}
$$

Maka dari itu, dalam menentukan singularitas ruang-waktu, harus dipastikan bahwa nilai skalar Kretschmann pada persamaan (4) juga bernilai tak hingga. Jika nilainya berhingga maka dipastikan singularitas pada titik tersebut merupakan singularitas semu.

Persamaan geodesik pada ruangwaktu merupakan lintasan tercepat pada permukaan kurva. Secara umum, persamaan geodesik pada permukaan melengkung yang tidak mendapatkan gaya luar diberikan sebagai berikut (Grön, 2011).

$$
\frac{d^{2} x^{\mu}}{d \lambda^{2}}+\Gamma_{\alpha v}^{\mu} \frac{d x^{\alpha}}{d \lambda} \frac{d x^{v}}{d \lambda}=0
$$

\section{HASIL DAN PEMBAHASAN}

Berdasarkan metrik ReissnerNordström pada persamaan (1), maka dapat diuraikan komponen-komponen tensor metrik pada setiap basis. Andaikan koordinat $(t, r, \theta$, $\phi)$ diberikan indeks $(0,1,2,3)$, maka komponen tensor metrik dapat dituliskan sebagai berikut.

$$
\begin{aligned}
& g_{00}=-\left(1-\frac{2 M}{r}+\frac{Q^{2}}{r^{2}}\right) \\
& g_{11}=\left(1-\frac{2 M}{r}+\frac{Q^{2}}{r^{2}}\right)^{-1} \\
& g_{22}=r^{2} \\
& g_{33}=r^{2} \sin ^{2} \theta
\end{aligned}
$$

Selanjutnya adalah menghitung simbol Christoffel menggunakan persamaan (8).
Hasilnya kita dapatkan nilai-nilai simbol Christoffel yang tidak nol sebagai berikut.

$$
\begin{aligned}
& \Gamma_{10}^{0}=\Gamma_{01}^{0}=\frac{M r-Q^{2}}{r\left(r^{2}-2 M r+Q^{2}\right)} \\
& \Gamma_{00}^{1}=\frac{\left(M r-Q^{2}\right)\left(r^{2}-2 M r+Q^{2}\right)}{r^{5}} \\
& \Gamma_{11}^{1}=\frac{Q^{2}-M r}{r Q^{2}-2 r^{2} M+r^{3}} \\
& \Gamma_{22}^{1}=-\frac{Q^{2}-2 M r+r^{2}}{r} \\
& \Gamma_{33}^{1}=-\frac{\sin ^{2} \theta\left(Q^{2}-2 r M+r^{2}\right)}{r} \\
& \Gamma_{12}^{2}=\Gamma^{2}{ }_{21}=\frac{1}{r} \\
& \Gamma_{33}^{2}=-\sin \theta \cos \theta \\
& \Gamma_{13}^{3}=\Gamma_{31}^{3}=\frac{1}{r} \\
& \Gamma_{23}^{3}=\Gamma_{32}^{3}=\cot \theta
\end{aligned}
$$

Menggunakan hasil simbol Christoffel dan persamaan (7) dapat dicari tensor kelengkungan Riemann yang tidak nol, yaitu

$$
\begin{aligned}
& R^{0}{ }_{110}=-\frac{3 Q^{2}-2 r M}{r^{2}\left(Q^{2}-2 r M+r^{2}\right)} \\
& R^{0}{ }_{220}=\frac{Q^{2}-r M}{r^{2}} \\
& R^{0}{ }_{330}=\frac{\left(Q^{2}-r M\right) \sin ^{2} \theta}{r^{2}} \\
& R^{1}{ }_{010}=-\frac{3 Q^{4}+\left(3 r^{2}-8 r M\right) Q^{2}+4 r^{2} M^{2}-2 r^{3} M}{r^{6}} \\
& R^{1}{ }_{221}=\frac{Q^{2}-r M}{r^{2}} \\
& R^{1_{331}}=\frac{\left(Q^{2}-r M\right) \sin ^{2} \theta}{r^{2}} \\
& R^{2}{ }_{020}=\frac{Q^{4}+\left(r^{2}-3 r M\right) Q^{2}+2 r^{2} M^{2}-r^{3} M}{r^{6}}
\end{aligned}
$$




$$
\begin{aligned}
& R^{2}{ }_{121}=-\frac{Q^{2}-r M}{r\left(r Q^{2}-2 r^{2} M+r^{3}\right)} \\
& R^{2}{ }_{332}=\frac{\left(Q^{2}-2 r M\right) \sin ^{2} \theta}{r^{2}} \\
& R^{3}{ }_{030}=\frac{Q^{4}+\left(r^{2}-3 r M\right) Q^{2}+2 r^{6}}{r^{6}} \\
& R^{3}{ }_{131}=-\frac{Q^{2}-r M}{r\left(r Q^{2}-2 r^{2} M+r^{3}\right)} \\
& R^{3}{ }_{232}=\frac{Q^{2}-2 r M+r^{2}}{r^{2}}-1
\end{aligned}
$$$$
R_{030}^{3}=\frac{Q^{4}+\left(r^{2}-3 r M\right) Q^{2}+2 r^{2} M^{2}-r^{3} M}{r^{6}}
$$

Berdasarkan tensor kelengkungan Riemman ini, dapat dicari tensor kelengkungan Riemann kovarian yang tidak nol menggunakan persamaan (5)

$$
\begin{aligned}
& R_{0110}=\frac{3 Q^{2}-2 r M}{r^{4}} \\
& R_{0220}=-\frac{\left(Q^{2}-2 r M+r^{2}\right)\left(Q^{2}-r M\right)}{r^{4}} \\
& R_{1221}=\frac{Q^{2}-r M}{Q^{2}-2 r M+r^{2}} \\
& R_{0330}=-\frac{\sin ^{2} \theta\left(Q^{2}-2 r M+r^{2}\right)\left(Q^{2}-r M\right)}{r^{4}} \\
& R_{1331}=\frac{\left(Q^{2}-r M\right) \sin ^{2} \theta}{Q^{2}-2 r M+r^{2}} \\
& R_{2332}=\left(2 r M-Q^{2}\right) \sin ^{2} \theta
\end{aligned}
$$

Menggunakan persamaan (6), didapat pula tensor kelengkungan Riemann kontravarian sebagai berikut.

$$
\begin{aligned}
& R^{0110}=\frac{3 Q^{2}-2 r M}{r^{4}} \\
& R^{0220}=-\frac{Q^{2}-r M}{r^{4}\left(Q^{2}-2 r M+r^{2}\right)} \\
& R^{1221}=\frac{\left(Q^{2}-r M\right)\left(Q^{2}-2 r M+r^{2}\right)}{r^{8}} \\
& R^{0330}=-\frac{Q^{2}-r M}{r^{4} \sin ^{2} \theta\left(Q^{2}-2 r M+r^{2}\right)}
\end{aligned}
$$

$$
\begin{aligned}
& R^{1331}=\frac{\left(Q^{2}-r M\right)\left(Q^{2}-2 r M+r^{2}\right)}{r^{8} \sin ^{2} \theta} \\
& R^{2332}=-\frac{Q^{2}-2 r M}{r^{8} \sin ^{2} \theta}
\end{aligned}
$$

Ketika sudah didapatkan tensor kelengkungan Riemann kovarian dan kontravarian, maka dengan demikian didapat nilai dari skalar Kretschmann berdasarkan persamaan (4) yaitu.

$$
K=\frac{56 Q^{4}-96 r M Q^{2}+48 r^{2} M^{2}}{r^{8}}
$$

Selanjutnya kita evaluasi nilai skalar Kretschmann pada titik-titik terjadinya singularitas. Berdasarkan tensor metrik pada persamaan (1) dan persamaan (3), secara umum terdapat 2 kemungkinan titik singularitas, yaitu $r=0$, dan $r_{ \pm}=M \pm \sqrt{M^{2}-Q^{2}}$, untuk $\mathrm{Q}^{2}>\mathrm{M}^{2}$, atau $\mathrm{Q}^{2}<\mathrm{M}^{2}$, dan $\mathrm{Q}^{2}=\mathrm{M}^{2}$

Untuk $r=0$, disubstitusikan ke persamaan (14) menghasilkan $K=\infty$. Ini berarti bahwa pada $r=0$, singularitas yang terjadi adalah singularitas nyata. Jelas bahwa pada titik pusat, terjadi penumpukan massa yang sangat massif yang menyebabkan kelengkungan ruang-waktu menjadi sangat tajam (Narayan and McClintock, 2008; Doeleman, 2008). Event horizon ini terjadi di hampir semua solusi metrik persamaan medan Einstein, yang tentu saja sangat remeh.

Untuk $\mathrm{Q}^{2}>\mathrm{M}^{2}$, maka nilai $r$ imajiner. Akan tetapi, jika disubstitusikan pada persamaan (14) akan menghasilkan $K \neq \infty$. Ini berarti bahwa singularitas yang terjadi pada titik tersebut untuk kasus $\mathrm{Q}^{2}>\mathrm{M}^{2}$ merupakan singularitas semu. Jika dilihat lebih jauh, pada kasus ini nilai koefisien $1-\frac{2 M}{r}+\frac{Q^{2}}{r^{2}}$ pada persamaan (1) selalu bernilai positif, sehingga metrik Reissner-Nordström secara umum lengkap. Koordinat $t$ selalu bersifat bak waktu, dan $r$ selalu bersifat bak ruang, namun tetap terdapat singularitas pada $r=0$ (Carroll, 2004). Pada titik tersebut tidak terdapat horizon peristiwa sehingga informasi yang masuk tidak memungkinkan keluar lagi. Terlihat pula pada $r$ mendekati tak hingga, solusi ReissnerNordström mendekati ruang-waktu datar.

Untuk $M^{2}>Q^{2}$, maka jika nilai $r$ pada kasus ini disubstritusikan ke persamaan (14) juga menghasilkan $K \neq \infty$. Ini berarti bahwa tetap singularitas yang terjadi merupakan singularitas semu. Pada kasus $M^{2}>Q^{2}$ maka 
koefisien $1-\frac{2 M}{r}+\frac{Q^{2}}{r^{2}}$ positif pada nilai $r$ yang besar dan $r$ yang kecil, namun negatif diantara nilai $r_{ \pm}=M \pm \sqrt{M^{2}-Q^{2}}$. Pada kasus ini, singularitas tetap terjadi pada $r=0$, namun sifatnya bak waktu, bukan bak ruang (Carroll, 2004).

Untuk kasus $M^{2}=Q^{2}$, maka nilai $r$ jika disubstitusikan pada persamaan (14) akan menghasilkan $K \neq \infty$. Berarti singularitas pada titik tersebut merupakan singularitas semu. Kasus ini sering disebut sebagai solusi ekstrim Reissner-Nordström. Pada titik ini, nilai koefisien $1-\frac{2 M}{r}+\frac{Q^{2}}{r^{2}}$ adalah nol. Ini merepresentasikan suatu horizon peristiwa, namun tidak bak waktu, melainkan bak ruang (Carroll, 2004). Hal menarik pada kasus ini adalah adanya keseimbangan antara massa dan muatan dari lubang hitam. Secara khusus, jika terdapat dua buah lubang hitam yang memiliki muatan sama (dengan tanda sama), akan saling tarik menarik secara gravitasi, namun saling menolak secara elektromagnetik, yang mana keduanya mungkin saling menghilangkan satu sama lain.

Dibandingkan dengan model lubang hitam bermuatan lainnya (Zhou and Liu, 2008; Hod, 2014), singularitas Reissner-Nordström memiliki sifat yang berbeda. Hal ini karena sumber partikel dianggap tidak berotasi. Kita tidak dapat mengetahui model metrik terbaik yang digunakan. Tetapi, tentu saja metrik apapun yang diajukan, tetap bukan merupakan solusi remeh dari persamaan Einstein.

Berdasarkan persamaan geodesik umum (13), dapat dituliskan persamaan geodesik untuk masing-masing koordinat $(t, r$, $\theta, \phi)$. Persamaan tersebut sangat penting untuk mengetahui dinamika partikel di sekitar area singularitas. Persamaan geodesik pada masing-masing koordinat akhirnya didapatkan sebagai berikut.

$$
\begin{gathered}
\left(1+\frac{Q^{2}-M r}{r Q^{2}-2 r^{2} M+r^{3}}\right) \frac{d^{2} r}{d \lambda^{2}}+ \\
\frac{\left(M r-Q^{2}\right)\left(r^{2}-2 M r+Q^{2}\right)}{r^{5}} \frac{d^{2} t}{d \lambda^{2}}- \\
\frac{Q^{2}-2 M r+r^{2}}{r} \frac{d^{2} \theta}{d \lambda^{2}}- \\
\frac{\sin ^{2} \theta\left(Q^{2}-2 r M+r^{2}\right)}{r} \frac{d^{2} \phi}{d \lambda^{2}}=0
\end{gathered}
$$


Narayan, R. and McClintock, J. E. (2008). Advection-dominated accretion and the black hole event horizon", New Astronomy Reviews. 51. 733-751.

O'neill, B. (1983). Semi-Riemannian Geometry, with applications to Relativity. California : Academic Press

Penrose, R. (1965). Gravitational Collapse and Space- Time Singularities", Physical Review Letters. 14(3). 57-59.

Wald, R. M. (1979). Construction of Metrik and Vector Potential Perturbations of a Reissner- Nordstrom Black Hole", Procedeings of the Royal Society A. Lond. 369. 67-81.

Zhou, S. and Liu, W. (2008). Hawking radiation of charged Dirac particles from a KerrNewman black hole", Physical Review D, 77, 1-6. 